\title{
Farm Along Application for Agriculture-India
}

\author{
Surisetty Lavanya ${ }^{1}$, Geethanjali Villuri ${ }^{2}$, Kavya Likhita Oleti ${ }^{3}$, \\ Charitha Rayapalli ${ }^{4}$ and Jyothsna Malla ${ }^{5}$ \\ IV B.Tech Student, Department of Computer Science and Engineering, Vignan's \\ Institute of Informatoion Technology (Autonomous), AP, Visakhapatnam, India \\ ${ }^{1}$ lavanya.ss@gmail.com, ${ }^{2}$ gitanjali.villuri04@gmail.com
}

\begin{abstract}
Farm Along is designed for the development of primary sector to bring back the past glory of the farmers of our Country. Farmers are the demigods of our country who are the main reason for our healthy living conditions. To bridge the gap between primary sector and secondary sector by identifying the drawbacks in agriculture we have come up with this idea. We are also concentrating on the solutions to bring awareness and guidance to farmers on the profitable utilization of land by using the same land for silviculture, livestock, animal husbandry and vertical farming. For providing the best guidance we will provide with various mentors and guides to be available for their queries and to teach them how to use our services and App. We have also provided the alternatives at the time of low demand for products such as cold storages to be in reach of all the farmers. Farm Along app is a very good platform for farmers who are not aware of some techniques to produce a better crop which would help them for their better lives. This app is available in their regional languages also in order to reach out larger sections of farmers.
\end{abstract}

Keywords: Farmer, Sustainable agriculture, Organic farming, Animal husbandry, Guides, Weather forecasting

\section{Introduction}

INDIA is known as the "KRISHAK PRADHAN DESH", where the farmer is treated as the demigod. Agriculture is the basic occupations in India where 3/4th of the population are dependent on Agriculture. 70 percent of people are dependent on agriculture for their livelihood. India is an agricultural country where most of the primary sector is based on agricultural products backing the economy. Agriculture was the advancement in the rise of human culture. India is among the top producers of several crops such as wheat, milk, jute, rice, pulses, sugarcane and cotton [1][2].

The Farm Along can help the farmers by giving on guidelines how to use fertilizers and pesticides and we can produce a quality living for animals. So that we can increase the income of farmers. Eventually, it increases the income of secondary and tertiary sector. Finally, we can increase revenue of the government by increasing the exports [3][4].

The main theme of Farm Along is to provide good nutrient food to this society and increase the Indian economy by the Agriculture.

Article history:

Received (April 15, 2019), Review Result (July 29, 2019), Accepted (September 28, 2019) 


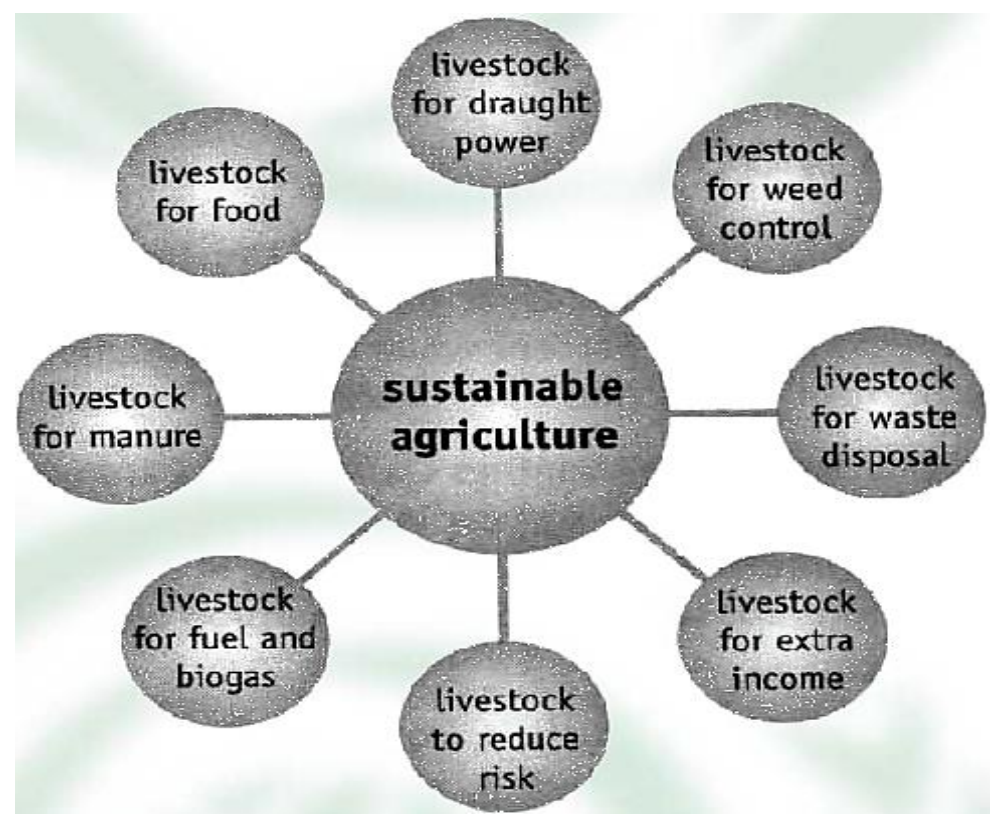

Figure 1. Role of agriculture

\section{Existing work}

We have made a presentation of our project proposal to let everyone understand the main objective of our idea and its services along with the features that will be provided by us. We are developing our Website and as of now we are ready with a Sample Website depicting its main features [5][6]. We have done a prototype of our Application and based on it we are building our Application. Hereby we are sure to develop our Application and Website within few months and start our services to all the interested people in and around our State and further for our Country too.

\section{Proposed work}

We are here to make primary sector as main source of income for future of our country in order to bring the past glory of spinal cord of our country (i.e. farmer). Imports can be reduced, by improving this sector, as well as an increase in exports leads to income. The main theme of this project is to make primary sector as the largest sector in the country.

\subsection{Bridge the communication gap}

We bridge the communication gap between farmers and buyers so as to improve the growth of farmers as well as helping in the buyer's business enhancement. In order to reduce the number of imports and increase the exports for the secondary sectors we have come up with this idea.

Industries search for its needs in certain places instead of that it can directly get the requirements related to agriculture from the farmers at the same place as farmers will be guided to do agriculture based on the type of land, available resources and guidance by the mentors to cultivate in an effective and efficient way. 
Table 1. Trade data for period 2006-07 to 2016-17 (P)

\begin{tabular}{|c|c|c|c|c|c|c|}
\hline S.No & Year & Exports & Growth (\%) & Imports & Growth (\%) & $\begin{array}{c}\text { Balance (In } \\
\text { Crores) }\end{array}$ \\
\hline 1 & $2006-2007$ & 571,779 & 25.28 & 840,506 & 27.27 & $-268,727$ \\
\hline 2 & $2007-2008$ & 655,864 & 14.71 & $1,012,312$ & 20.44 & $-356,448$ \\
\hline 3 & $2008-2009$ & 840,755 & 28.19 & $1,374,436$ & 35.77 & $-533,680$ \\
\hline 4 & $2009-2010$ & 845,534 & 0.57 & $1,363,736$ & 0.78 & $-518,202$ \\
\hline 5 & $2010-2011$ & 113,6964 & 34.47 & $1,683,467$ & 23.45 & $-879,504$ \\
\hline 6 & $2011-2012$ & $1,455,959$ & 28.94 & $2,345,463$ & 339.32 & $-1,034,844$ \\
\hline 7 & $2012-2013$ & $1,634,318$ & 11.48 & $2,669,162$ & 13.8 & $-810,738$ \\
\hline 8 & $2013-2014$ & $1,905,011$ & 16.56 & $2,715,434$ & 1.73 & $-840,739$ \\
\hline 9 & $2014-2015$ & $1,896,348$ & -0.45 & $2,737,087$ & 0.8 & $-773,920$ \\
\hline 10 & $\begin{array}{c}2015-2016 \\
\text { (Provisional) }\end{array}$ & $1,716,378$ & -9.49 & $2,490,298$ & 9.02 & $-503,079$ \\
\hline 11 & $\begin{array}{c}2015-2016(\text { April- } \\
\text { October) }\end{array}$ & 998,212 & - & $1,501,291$ & - & $-356,554$ \\
\hline
\end{tabular}

\subsection{Profitable utilization of land}

Multi-usage of land refers to the practice of using the land for more than one purpose. The land need not be restricted to only agriculture domain. It can be used for many types it can be pisciculture, silviculture, cattle rearing etc.

PROBLEM: A farmer cannot raise a crop throughout the year due to varied reasons. The weather and climatic conditions or his financial conditions may not support him. But the farmer has to earn his bread and butter from the land only. During such situations multi-usage of land will help him.

SOLUTION: Such helpless situations of the framer can be overcome by opting for the practices of multi-usage of land.

Silviculture: It refers to the practice of growing trees in the pastureland. It also increases the crop production as well as the crop yield as they protect the crops from huge winds etc.

Livestock: Live-stock means the method of raising domesticated animals in an agricultural setting to produce commodities like milk, eggs etc.

Apiculture: Apiculture is the maintenance of bee colonies in man-made hives. This is a commercially viable practice for the farmers during the non-cropping seasons.

Vertical farming: A farmer with less land can also get profits by practicing vertical farming on the small piece of land that they have. A farmer can get profits if he does multi utilization of his land by practicing pisciculture, horticulture, animal husbandry and other kinds of practices at a time. This leads to the best profitable utilization of the land, thereby increasing the growth in the standards of agriculture. 


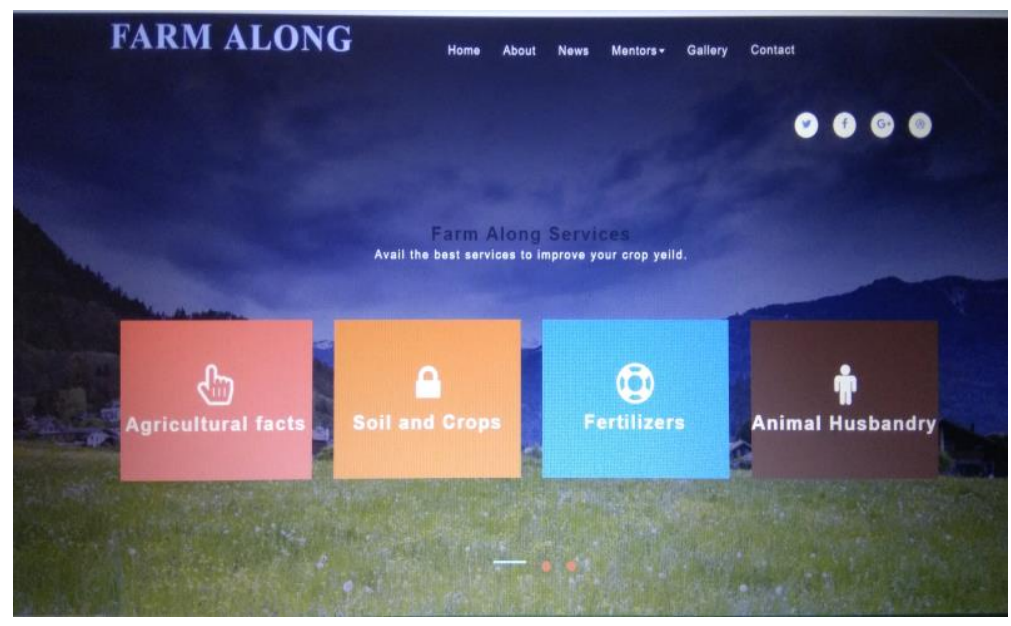

Figure 2. FARM ALONG website

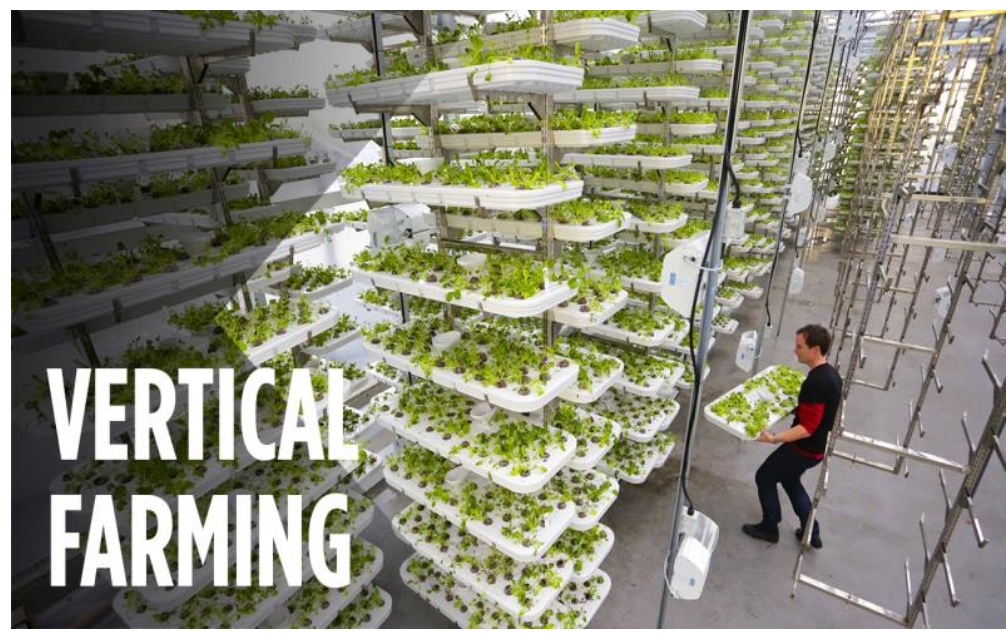

Figure 3. Vertical farming

We give all the information to initiate these methods and guide them throughout their work.

\subsection{Alternatives at the time of low demand for products}

Cold storage is a special kind of place, the temperature of which it is kept very low. Depending upon the type of commodity, the temperature in cold storage is maintained such as in refrigerated storage. There are lots of different products that need cold storage to stay in a good condition. The products stored in cold storage are mainly used during floods and are given a very low price. Farmers get low price when compared to their production due to the lack of demand of that crop in the area which it is cultivated.

But now we are using cold storage in a different way such as we recommend farmers a crop which is in demand. The recommended crop may not be profitable in the area where it is cultivated, so we will store that product in the cold storage and export to the place where the demand for that crop is high. 


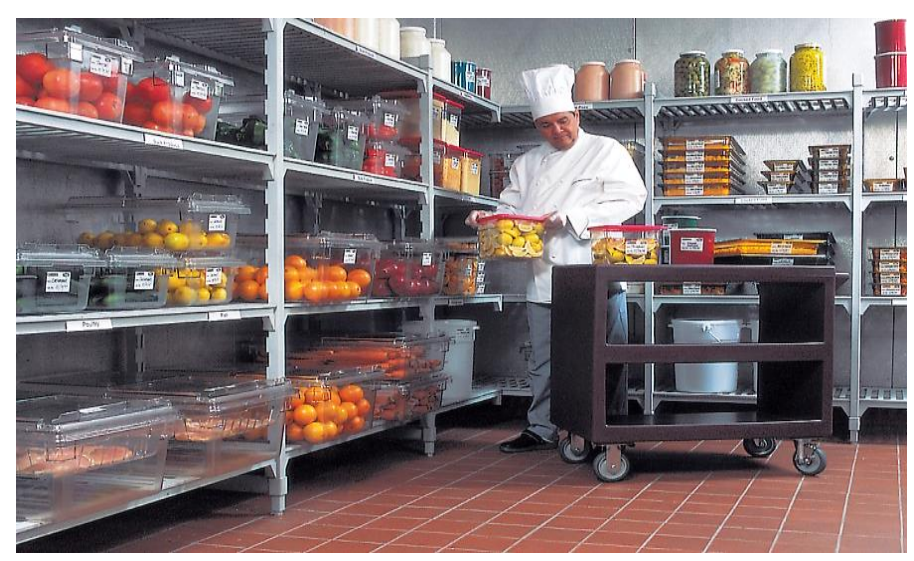

Figure 4. Cold storage

\subsection{Outcome}

The FARM ALONG is an innovative approach of helping a farmer to improve his yield along with the profits. Its services are put forward through an android app and a website in order to reach out larger sections of people.

The Farm Along Website will guide the farmers by giving the updates of government schemes and website also encourages the farmers who are willing to opt for the latest technologies and advanced methods of farming. Eg: Organic farming. These are economically feasible and commercially profitable for the farmers.

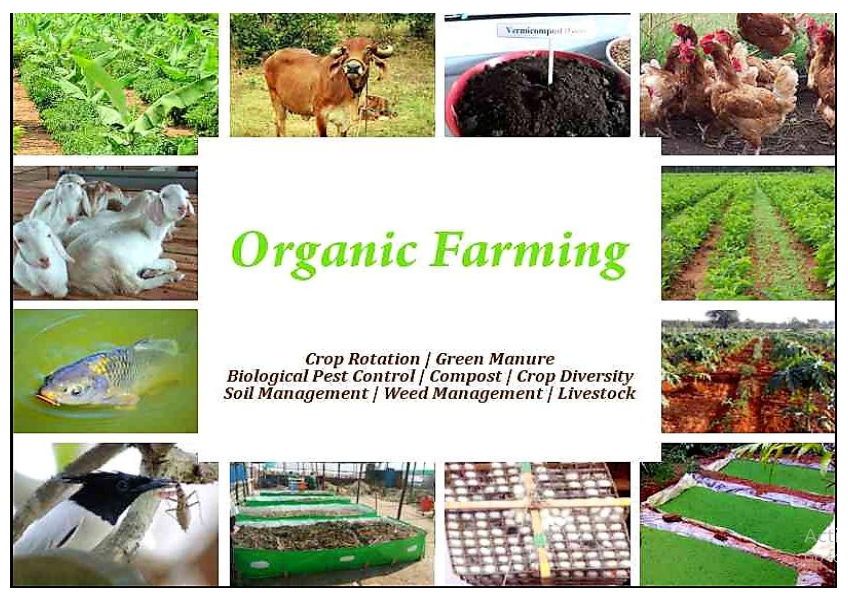

Figure 5. Organic farming example 1

The utilization of mobile phones in rural areas especially for farmers also increased a lot. The people whose education is very less also utilizing these mobile phones and other communication devices. As a result of this, the development of applications and other mobilebased applications might increase the reach of the public in a bigger way. As a result, the data might be reached to all the people who are staying in rural India. In the current application, the basic details about various sorts of agriculture and related topics like the growing of goats, hens, horticulture, sericulture and other types etc. For example, in order to cultivate or grow the fisheries, several steps to be followed for better output or for better yields from these fisheries. The type of land selection, contents in the land like the type of soil, water quality under the soil, 
the amount of chemicals or other pesticides present under this soil, the flow of water and the contaminants in the underground water etc., points to be considered very serious and important as they are going to influence the growth of these fisheries and their life in such waters.

If the groundwater is fully contaminated, even though several steps were taken to grow the fisheries a fro better yields the output yield may not satisfy the farmers. This application is a very boost and helpful application for the farmers for their day to day activities can be made more effectively and efficiently for yielding the better results and better growth from the crops and fields.

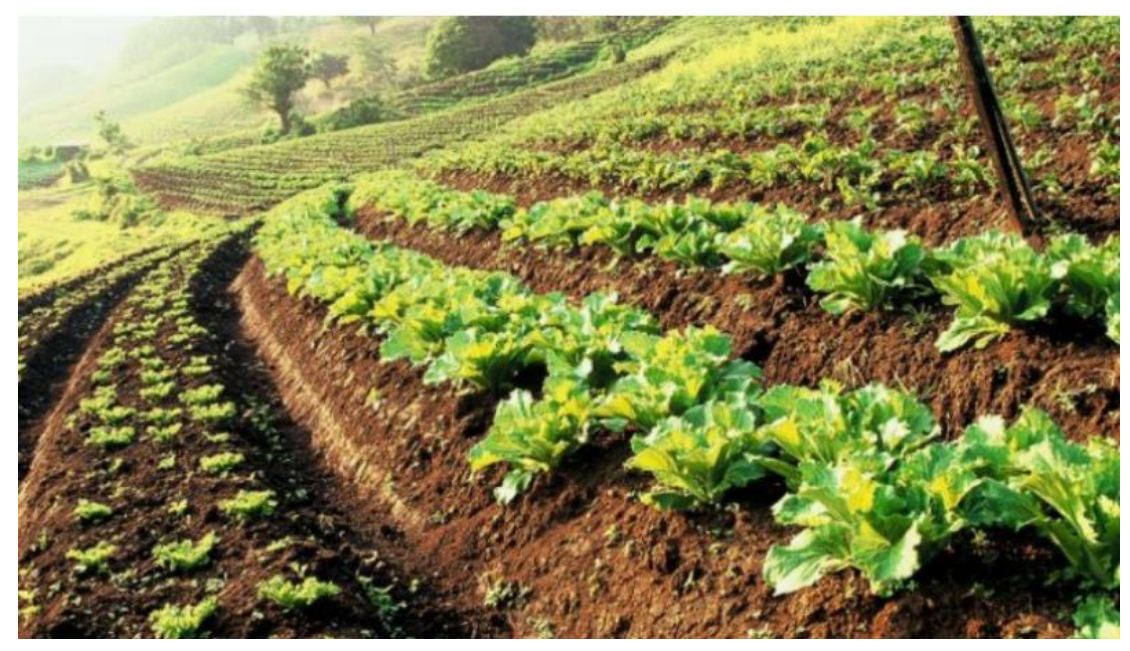

Figure 6. Organic farming example 2

The other important steps to be followed or to be taken are the growing measures for various types of crops and preventive measures for not being affected with virus or with other sort problems like the less growth of crops, less production, taking more water etc. In the current application, an attempt has been made to provide the basic steps and preventive measures to be followed for the better growth and for better production from the crops by following good and basic precautions and steps in the span of growing all these sorts of various crops at various places. The major goal is to reach more number of farmers with best suggestions and other ideas to get good and best quality of production from their crop fields.

\section{Conclusion}

Finally, concluding that Farm Along app is a very good platform for farmers who are not aware of some techniques to produce a better crop which would help them for their better lives. This app is available in their regional languages also in order to reach out larger sections of farmers. This idea would provide suitable crops for the land and quality pesticides to avoid damage to the crop.

The main theme of this farm along is allowing farmers to know about new ideas for better crop production. This is done through the concept of mentoring. Mentors do help the farmers to let know about all the services provided and best guidelines which help for production of better crop. In this, it is concluded that this proposed system provides user-friendly environment to the illiterate farmer of India as system provide information in local language. 


\section{References}

[1] Mywish K. Maredia and David A. Raitzer, "Review and analysis of documented patterns of agricultural research impacts in Southeast Asia," Agricultural Systems, vol.106, pp.46-58, (2012) DOI: 10.1016/j.agsy.2011.10.011

[2] Rajeswari. S., "Agricultural research effort: Conceptual clarity and measurement," World Development, vol.23, no.4, pp.617-635, (1995) DOI:10.1016/0305-750X(95)00002-T

[3] Roy Macload and Deepak Kumar, "Technology and the Raj," Sage Publication India Pvt. Ltd, (1995)

[4] Singh Organisation for Crop Improvement in India, "In: Plant Breeding: Principles and Methods," Kalyani Publishers, Ludhiana, pp.801-830, (2001)

[5] Indian Council of Agricultural Research, http://www.icar.org.in/, (2019)

[6] Planning Commission Government of India, (2017) 
Farm Along Application for Agriculture-India

This page is empty by intention. 